\title{
MODEL SÜTLÜ TATLIDA HOMOJEN OLMAYAN DAĞILIM İLE YAĞ AZALTMA
}

\author{
Müge Baysal, Yeşim Elmaci* \\ Ege Üniversitesi, Mühendislik Fakültesi, Gıda Mühendisliği Bölümü, İzmir, Türkiye \\ Geliş / Received: 19.02.2021; Kabul / Accepted: 02.07.2021; Online bask1 / Published online: 14.07.2021
}

Baysal, M., Elmac1, Y. (2021). Model sütlü tatlıda homojen olmayan dağılım ile yağ azaltma. GIDA (2021) 46 (4) 1016-1025 doi: 10.15237/gida.GD21038

Baysal, M., Elmacr, Y. (2021). Fat reduction by inhomogeneous distribution in model dairy dessert. GIDA (2021) 46 (4) 1016-1025 doi: 10.15237/gida.GD21038

\section{ÖZ}

Bu çalışmada, model sütlü tatlıda katmanlı bir yapı oluşturularak homojen olmayan dağılım ile yağ azaltma amaçlanmıştır. Bu amaçla, $\% 5$ yağ içeriğine sahip model sütlü tatlı ve yağ içeriği $\% 25$ ve $\% 30$ azalacak şekilde homojen ve inhomojen dağılıma sahip sütlü tatl formülasyonları hazırlanmıştır. Aynı yağ içeriğine sahip homojen örneklerin $L^{*}$ değerinin inhomojen örneklerin $L^{*}$ değerinden daha yüksek olduğu saptanmıştır. Örneklerin $a^{*}$ ve $b^{*}$ değerlerinin sırasıyla -2.07 ile -2.51 ve 10.86-12.63 arasında değiştiği ve yağı azaltılmış örneklerin sertlik, dış yapışkanlık, iç yapışkanlık, sakızımsılık, çiğnenebilirlik ve esneklik değerleri arasında fark olmadığı saptanmıştır. Yağ içeriği \%25 azaltılmış homojen ve inhomojen yapıdaki formülasyonların görünüş ve ağızda algılanan kıvam değerleri diğer formülasyonlara göre daha yüksek belirlenmiştir. İnhomojen yapıda, yağ içeriği \%25 azaltılmış tatlı örneğinin lezzet açısından en çok tercih edildiği tespit edilmiştir. Çalışma sonucunda, inhomojen katmanlı yapı ile yağ içeriği azaltılmış model sütlü tatllların homojen dağllım gösteren örneklere göre daha fazla tercih edildiği belirlenmiştir.

Anahtar kelimeler: Sütlü tatlı, yağ azaltma, inhomojen dağıllım, homojen olmayan dağ1lım

\section{FAT REDUCTION BY INHOMOGENEOUS DISTRIBUTION IN MODEL DAIRY DESSERT}

\begin{abstract}
The aim of this study was to reduce the fat content of model dairy desert using inhomogeneous distribution by creating a layered structure. For this purpose, a dairy dessert with $5 \%$ fat content was chosen as a model, and homogeneous and inhomogeneous distribution formulations were prepared so that the fat content was reduced by 25 and $30 \%$. The $L^{*}$ value of the homogeneous samples with the same fat content was determined to be higher than the $L^{*}$ value of the inhomogeneous samples. The $a^{*}$ and $b^{*}$ values of the samples varied between -2.07 and -2.51 and 10.86-12.63, respectively. No difference was determined between the hardness, adhesiveness, cohesiveness, gumminess, chewiness, and resilience values of the reduced-fat samples. Appearance and consistency in mouth of $25 \%$ reduced fat content homogeneous and inhomogeneous formulations were determined to be higher than other formulations. As a result of the study, it was determined that inhomogeneous layered structure model dairy desserts with reduced fat content were preferred more than the homogeneous distribution samples.
\end{abstract}

Keywords: Dairy dessert, fat reduction, inhomogeneous distribution, non-homogeneous distribution

\footnotetext{
*Yazışmalardan sorumlu yazar/Corresponding author;

$\triangle$ yesim.elmaci@ege.edu.tr
}

(D) (+90) 2323111316

Müge Baysal; ORCID no: 0000-0001-7197-4302

Yeşim Elmacl; ORCID no: 0000-0001-7164-838X 


\section{GİRIŞ}

Günümüzde obezite ve aşırı kilo, dünya çapında giderek artan bir sağlık sorununa dönüşmekte olup bu durum koroner kalp hastalıkları, yüksek tansiyon, bazı kanser türleri, tip 2 diyabet gibi metabolik bozuklukların gelişmesinin temelini oluşturmaktadır. Bununla birlikte beslenme, sağlık, kilo kontrolü, tüketicilerin fiziksel ve ruhsal sağlığını artırma gibi çeşitli nedenlerle düşük kalorili ürünlere yönelik tüketici talebinin arttığ1 görülmektedir (Serdaroğlu ve Tömek, 1995; Siró vd., 2008-; Bayarri ve Costell, 2009; Munsters ve Saris, 2014). Tüketiciler, yeterli vücut ağırllğını korumak ve sağliklı fiziksel yapıya sahip olmak için yeterli duyusal özelliklere sahip sağlıklı yiyecekleri tercih etmektedir (Verbeke, 2006). Gıda endüstrisi tüketici tercihlerini karşılayacak düşük kalorili, sağlıklı gıda formülasyonlarına ihtiyaç duymaktadır.

Gıda ürünlerinde yağ azaltma, genellikle gidaların yapısal özelliklerinde istenmeyen değişikliklere neden olmaktadır. Gıda formülasyonlarında yağ içeriğinin azaltılmasına yönelik önerileri dikkate almak için çeşitli stratejiler geliştirilmiştir. Ancak meydana gelen değişikliklerle, yeniden biçimlendirilmiş gidanın tüketici tarafindan kabul edilebilir olması önem taşımaktadır (Syarifuddin vd., 2016). Bu durum göz önüne alındığında, düşük yağ içerikli ürünlerin geliştirilmesi, gıda üreticileri için bir zorluk olmaya devam etmektedir. Lezzet algisını bozmadan tüketicinin istediği düşük yağlı gida üretimi için birçok çalışma yapılmakta ve bazı çalışmalarda yăg içeriğinin model sistemlerin mekanik ve duyusal özellikleri üzerindeki etkisi bildirilmektedir (Mosca vd., 2012). Gidalarda yağ azalması ile ortaya çıabilecek sorunları telafi etmek ve istenen özellikleri sağlamak için en çok kullanılan stratejilerden biri, yağ ikameleri veya yağ taklitlerinin kullanılmasıdır. Ayrıca çeşitli yağ ikamelerinin belirli kombinasyonları hazırlanarak da bu durum sağlanabilmektedir (Doğan ve Küçüköner, 1999; Sandrou ve Arvanitoyannis, 2000). Süt bazlı ürünlerde, kısa ve uzun zincirli inülin karışımları (Arcia vd., 2011; Rodriguez Furlan ve Campderros, 2017), süt proteinleri (Borreani vd., 2017; Torres vd., 2018), polidekstroz (Güzeler vd., 2011), soya proteinleri (Liu vd., 2018), maltodekstrin (Güzeler vd., 2011), $\lambda$-carrageenan (Bayarri vd., 2010) yağ ikamesi olarak yaygın bir şekilde kullanılmaktadır.

Gıdalardaki yağ, şeker ve tuzun azaltılması için geliştirilen yöntemlerden biri de, homojen olmayan dağılım ile algilanan tat yoğunluğunu arttırmaktır. Homojen olmayan dağılım, gıda matrisinde değişen konsantrasyonlarda yăg, şeker, tuz gibi ürünlerin eklenmesi ile gida matrisinin tamamında aynı özelliği göstermeyen farklı katmanlı yapıların oluşturulmasıdır. Jel tabakalarından oluşan bir model sistem kullanılarak yapılan bir çalışmada, şekerin homojen olmayan dağılımının algilanan tatlilık yoğunluğu üzerindeki etkisi araştırılmış homojen olmayan dağılım ile algilanan tatlilık yoğunluğunda azalma olmadan \%20 oranında şeker içeriğinin azaltılabileceği tespit edilmiştir (Mosca vd., 2010). Tuzlu atıştırmalık yiyecekler üzerinde yapılan başka bir çalışmada homojen olmayan dağılıma sahip atıştırmalıklar, homojen yapıda olan ve tuz içeriği $\% 25$ oranında arttırılan atştırmalıklara göre daha tuzlu bulunmuştur (Emorine vd., 2013).

$\mathrm{Bu}$ çalş̧mada, homojen olmayan dağılım kullanılarak yağ azaltmanın etkisinin belirlenmesi amaçlanmıştır. Bu amaçla model sistem olarak sütlü tatlı seçilmiş ve yağ azaltmanın etkisi, homojen olmayan dağglıma sahip katmanlı bir yap1 oluşturularak araştırılmıştır. Homojen (HOM) ve homojen olmayan (INHOM) dağllima sahip sütlü tatlılar, \%25 ve $\% 30$ oranında yağ içeriği azaltılarak hazırlanmıştır. Son yıllarda yapılan homojen olmayan dağılımla, şeker ve tuz oranını azaltmaya yönelik çalışmalar yapilmakla birlikte yağ ile ilgili bir çalışmaya rastlanmamıştır. Model sütlü tatlıda homojen olmayan bir yap1 oluşturularak yağ içeriğinin azaltılmasının özgün bir çalışma olduğu ve literatüre katkı sağlayacağı düşünülmektedir.

\section{MATERYAL VE YÖNTEM}

\section{Materyal}

Model sütlü tatlı üretiminde yağsız süt (\%0.1 yağlı) (Pınar Süt Mamülleri San. A.Ş.), mısır nişastası (Migros Ticaret A.Ş.), toz şeker (Migros Ticaret A.Ş.), ve su bazlı çilek aroması (Aromsa, Besin Aroma ve Katkı Maddeleri San. ve Tic. A.Ş.) materyal olarak kullanılmıştır. Model 
formülasyonda yağ oranının ayarlanması için yağ emülsiyonu hazırlanmış ve bu emülsiyon için ayçiçek yağ1 (Migros Ticaret A.Ş.), ve peynir altı suyu proteini (whey protein) (Hard Line Nutrition, Kavi Gıda San. ve Tic. Ltd. Şti.) kullanılmıştır.

\section{Yağ emülsiyonunun hazırlanması (o/w)}

Model sütlü tatlı üretiminde kullanılacak su içinde yağ emülsiyonu hazırlanırken ağırlıkça \%1 peynir alt1 suyu proteini içeren su fazı manyetik bir karıştırıcıda 400 rpm'de 5 dakika karıştırılarak homojen hale getirilmiştir. Daha sonra karışıma damla damla ağırlıkça \%40 ayçiçek yağı ilave edilmiş ve Ultra Turrax karıştırıcıda (Ultra Turrax T25, IKA) 12000 rpm'de yaklaşı 2 saat homojenize edilmiş ve emülsiyon oluşturulmuştur. Daha sonra bu karışım yüksek basınçlı homojenizasyona tabi tutulmuş, yüksek basınçlı homojenizasyon işlemi (GEA Lab Homojenizatör Panda PLUS 2000) ilk geçişte 150 bar basinç uygulanarak ve 3 geçişte toplam 550 bar basınç uygulanarak gerçekleştirilmiştir. Elde edilen emülsiyon karışım1, $4^{\circ} \mathrm{C}^{\prime} \mathrm{de}$ buzdolabı koşullarında muhafaza edilmiş ve bozulmadan yaklaşık bir hafta süreyle buzdolabında dayanıklılı̆ını sürdürmüştür.

\section{Model sütlü tatlı formülasyonunun hazırlanması}

Yağsız süte (0.1 yağ) toz şeker, misır nişastas1, emülsiyon karışımı ve çilek aroması (su bazlı) ilave edilerek elde edilen karışım, homojen hale gelene kadar oda sıcaklığında 1-2 dakika karıştırllmıştır. Elde edilen karışım kısık ateşte yavaş yavaş pişirilmiştir ve karışım $75^{\circ} \mathrm{C}$ de koyulaştıktan sonra 1-2 dakika daha karıştırılarak ocaktan alınmıştır. Daha sonra tatlı örnekleri 50 gr'lık tatlı kaplarına doldurularak oda şartlarında soğumaya bırakılmıs ve soğutulduktan sonra buzdolabinda bekletilmiştir.

Kontrol örneği (\%5 yağlı), yağ içeriği $\% 25$ azaltılmış HOM ve İNHOM ile yağ içeriği \%30 azaltılmış HOM ve INHOM örnekleri hazırlanmıştır. Yă̆ içeriği homojen dağılım göstermeyen sütlü tatlıların hazırlanmasinda tatlılar 3 ayrı katman oluşturacak şekilde kaplara doldurulmuştur. Alt ve üst katmanların yağ içeriği eşit tutularak ve sadece orta katmanın yağ içeriği sıfır olacak şekilde INHOM örnekler hazırlanmıştır. Hazırlanan Kontrol, HOM3.5, INNHOM 3.5, HOM3.75, INHHOM3.75, model tatlı örneklerinin katmanlı yapısının gösterimi sırasıyla Şekil 1, Şekil 2 ve Şekil 3 'te verilmiştir. Çizelge 1'de model sütlü tatlı formülasyonları verilmiştir.

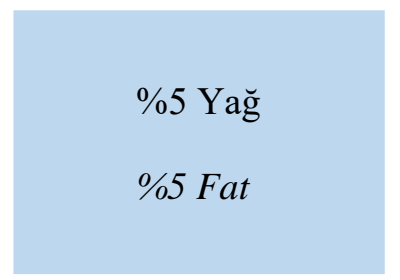

Şekil 1. Homojen dağılıma sahip yağ içeriği $\% 5$ olan kontrol örneği kesiti

Figure 1. The control sample with 5\% fat content with bomogeneous distribution

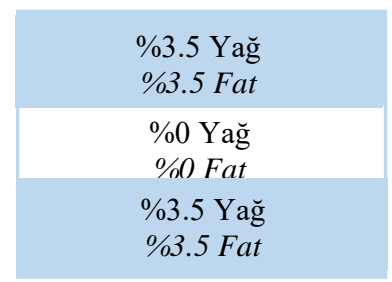

(a)

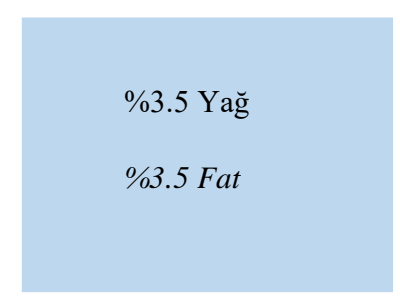

(b)
Şekil 2. a) Homojen dağılıma sahip olmayan yağ içeriği \%30 (INHOM3.5) azaltılmış model sütlü tatlı kesiti b) Homojen dağılıma sahip olan yağ içeriği \%30 azaltılmıs (HOM3.5) model sütlü tatlı kesiti

Figure 2. a) 30\% reduced fat inhomogeneous (INHOM3.5) model dairy desert b) $30 \%$ reduced fat bomogeneous (HOM3.5) model dairy desert

\%3.75 Yağ
$\% 3.75$ Fat
$\% 0$ Yağ
$\% 3.75$ Yağ
$\% 3.75$ Fat

(a)

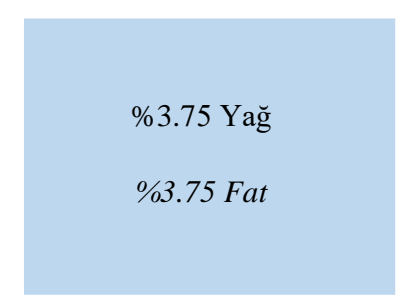

(b)
Şekil 3. a) Homojen dağılıma sahip olmayan yağ içeriği \%25 azaltılmış (INHOM3.75) model sütlü tatl kesiti b) Homojen dağılıma sahip olan yağ içeriği \%25 azaltılmış (HOM3.75) model sütlü tatlı kesiti Figure 3. a) $25 \%$ reduced fat inhomogeneous (INHOM3.75) model dairy desert b) 25\% reduced fat bomogeneous (HOM3.75) model dairy desert 
Çizelge 1. Model sütlü tatlı üretiminde kullanılan formülasyonlar Table 1. Formulations used in the production of model dairy desserts

\begin{tabular}{|c|c|c|c|c|c|c|c|}
\hline & $\begin{array}{c}\text { Model } \\
\text { formülasyon } \\
\text { Model } \\
\text { formulation }\end{array}$ & \multicolumn{3}{|c|}{$\begin{array}{c}\text { Yağ içeriğ } \% \text { \% } 25 \text { azaltılmış } \\
25 \% \text { reduced fat content }\end{array}$} & \multicolumn{3}{|c|}{$\begin{array}{c}\text { Yağ içeriğ } 1 \% 30 \text { azaltılmış } \\
30 \% \text { reduced fat content }\end{array}$} \\
\hline & $\begin{array}{l}\text { Kontrol } \\
\text { Control }\end{array}$ & \multicolumn{2}{|c|}{$\begin{array}{l}\text { INHOM } \\
\text { INHOM }\end{array}$} & $\begin{array}{l}\mathrm{HOM} \\
\text { HOM }\end{array}$ & \multicolumn{2}{|c|}{$\begin{array}{l}\text { INHOM } \\
\text { INHOM }\end{array}$} & $\begin{array}{l}\mathrm{HOM} \\
\mathrm{HOM}\end{array}$ \\
\hline $\begin{array}{l}\text { Materyal } \\
\text { Material }\end{array}$ & $\begin{array}{l}\text { Miktar (g) } \\
\text { Amount }\end{array}$ & $\begin{array}{c}\text { \%3.75 } \\
\text { yağlı } \\
\text { katman } \\
\text { Layer with } \\
3.75 \% \text { fat }\end{array}$ & $\begin{array}{l}\% 0 \text { yağlı } \\
\text { katman } \\
\text { Layer with } \\
\text { O\% fat }\end{array}$ & & $\begin{array}{c}\text { \%3.5 } \\
\text { yağlı } \\
\text { katman } \\
\text { Layer with } \\
3.5 \% \text { fat }\end{array}$ & $\begin{array}{l}\% 0 \text { yağlı } \\
\text { katman } \\
\text { Layer with } \\
\text { O\% fat }\end{array}$ & \\
\hline $\begin{array}{lll}\text { Yağsız süt } & (0.1 \\
\text { yağlı) (g) } & & \\
\text { Skimmed } & \text { milk } & (0.1 \\
\text { fat) } & & \end{array}$ & 176.64 & 176.64 & 176.64 & 176.64 & 176.64 & 176.64 & 176.64 \\
\hline $\begin{array}{l}\text { Toz şeker (g) } \\
\text { Granulated sugar }\end{array}$ & 16 & 16 & 16 & 16 & 16 & 16 & 16 \\
\hline $\begin{array}{l}\text { Misır nişastası }(\mathrm{g}) \\
\text { Corn starch }\end{array}$ & 10 & 10 & 10 & 10 & 10 & 10 & 10 \\
\hline $\begin{array}{l}\text { Çilek aroması (su } \\
\text { bazli) (g) } \\
\text { Strawberry flavor } \\
\text { (water based) }\end{array}$ & 0.2315 & 0.2236 & 0.2236 & 0.2236 & 0.2220 & 0.2220 & 0.2220 \\
\hline $\begin{array}{l}\text { Emülsiyon karişımı } \\
(\mathrm{o} / \mathrm{w})(\mathrm{g}) \\
\text { Emulsion mixture } \\
(\mathrm{o} / \mathrm{w})\end{array}$ & 28.95 & 20.96 & - & 20.96 & 19.43 & - & 19.43 \\
\hline
\end{tabular}

\section{Yöntem}

\section{Kimyasal analizler}

Model sütlü tatlı örneklerinin kuru madde analizi (AOAC, 1995) gravimetrik yöntem ile, yağ içeriği ise AACC (1990)'a göre Soxhlet tekniği kullanılarak çözücü ekstraksiyonu ile gerçekleştirilmiştir.

\section{Renk analizi}

Model sütlü tatlı örneklerinin rengi, $L^{*}, a^{*}$ ve $b^{*}$ koordinat sistemi kullanılarak renk ölçüm cihazı (Konica Minolta CR 400, Japonya) ile belirlenmiştir (Peker ve Arslan, 2013). Her bir örnek için 4 farklı noktadan ölçüm alınarak renk analizi gerçekleştirilmiştir. Ayrıca tatlı örnekleri karıştırilıp homojen hale getirilerek renk ölçümleri yapılmışıtır.

\section{Doku analizi}

Model sütlü tatlı örneklerinin dokusal özelliklerinin belirlenmesi doku analizörü (TA.XT Plus, Stable Micro Systems, Ltd. Surry, İngiltere) kullanılarak gerçekleştirilmiştir. Sertlik belirlemek amacıyla sıkıştırma uygulanmıştır (Aytaç, 2017). Örneklerin sertliğini belirlemek için paslanmaz çelik $30 \mathrm{~mm}$ perspeks silindir prob $\mathrm{P} / 30 \mathrm{P}$ kullanılmıştır. Analizde kullanılan ölçüm parametreleri; yük hücresi $5 \mathrm{~kg}$, test hızı $2 \mathrm{~mm} / \mathrm{s}$, mesafe $10 \mathrm{~mm}$, tetikleme kuvveti $5 \mathrm{~g}$ olarak ayarlanmıştır.

\section{Duyusal analiz}

Homojen ve homojen olmayan dağılım gösteren model sütlü tatlı örnekleri arasinda fark olup olmadığını belirlemek için eşlenmiş kıyaslama testi uygulanmıştır. Ayrıca tatlı örneklerinin kalite farklilıklarını ve farklılık derecelerini belirlemek için puanlama testi uygulanmıştır (Altuğ Onoğur ve Elmac1, 2015). Bu amaçla, 20 panelist tarafından görünüş, lezzet, ağızda kıvam ve genel beğeni 5 puanlık bir değerlendirme ölçeği kullanarak değerlendirmiştir. Panelistler duyusal değerlendirme sırasında tatlı örneklerinin en üst tabakasindan en alt katmanına kadar örnekten alarak tadımı gerçekleştirmişlerdir. Çizelge 2'de, kullanılan değerlendirme formu verilmektedir. 
Çizelge 2. Çilek aromalı sütlü tatlı duyusal değerlendirmesinde kullanılan form Table 2. Sensory evaluation form of strawberry flavored dairy dessert

Görünüş Appearance

5- Parlak krem rengi, pürüzsüz düzgün yapı, kaşıktan kolay ayrılmayan kıvamda

5- Bright creamy color, smooth and uniform structure, in a consistency that does not easily separate from the spoon

4- Parlak krem rengi, pürüzsüz düzgün yapıda hafif azalma, kaşıktan kolay ayrılmayan kıvamda

4- Bright creamy color, slight decrease in smooth, uniform structure, in a consistency that does not easily separate from the spoon

3- Parlak krem rengi, pürüzsüz düzgün yapıda azalma, kaşıktan hafif kolay ayrılan kıvamda

3- Bright creamy color, decrease in smooth, uniform structure, in a consistency that easily separated from the spoon

2- Hafif mat krem rengi, düzgün olmayan yapı, kaşıktan kolay ayrılan kıvamda

2- Light matte creamy color, non-uniform structure, in a consistency that easily separated from the spoon

1- Yüzeyde değişik renk oluşumu, düzgün olmayan yapı, kaşıktan kolay ayrılan kıvamda

1-Different color formation on the surface, non-uniform structure, in a consistency that easily separated from the spoon

\section{Lezzet Flavor}

5- Kendine özgü tipik çilekli muhallebi lezzetinde

5- Unique typical strawberry dairy dessert flavor

4- Cilekli muhallebi lezzetinde hafif azalma

4- Slight decrease in strawberry dairy dessert flavor

3- Çilekli muhallebi lezzetinde hafif azalma, hafif margarin lezzeti

3-Slight decrease in strawberry dairy dessert flavor, slight margarine flavor

2- Çilekli muhallebi lezzetinde hafif azalma, margarin lezzetinde artış

2- Slight reduction in strawberry dairy dessert flavor, increase in margarine flavor

1- Çilekli muhallebi lezzetinde azalma, margarin lezzeti

1- Decrease in strawberry dairy dessert flavor, margarine flavor

Ağızda Kıvam (Kremamsı Yap1, Pürüzlülük, Yapışkanlık) Consistency in Mouth (Creamy texture, smoothness, stickiness)

5- Kendine özgü kremamsı doku ve yayılmayan yapıda

5- Unique creamy texture and non-spreadable structure

4- Kendine özgü kremamsı doku, hafif yayılan yapıda

4- Unique creamy texture and slightly spreadable structure

3- Kremamsi dokuda hafif azalma, yayılan yapıda

3- Slight decrease in creamy texture, spreadable structure

2- Kremamsı yapıda azalma, ağza yapışan veya hiç yapışmayan yapıda

2- Decrease in creamy texture, sticky or non-sticky structure in the mouth

1- Kremamsı yapıda azalma, ağza çok sıvaşan veya hiç sıvaşmayan ve yayılmayan

1- Decrease in creamy texture, very sticky or non-sticky structure in the mouth

5- Çok Beğendim

Genel Beğeni Overall Acceptability

5- Like very much

4- Beğendim

4- Like

3- Biraz Beğendim

3- Like a little

2- Beğenmedim

2- Dislike

1- Hiç Beğenmedim

1- Dislike extremely

\section{İstatistiksel analiz}

Verilerin istatistiksel değerlendirmesi SPSS 25.0 paket programı ile $\% 95$ güven aralığında yapılmıştır. Çilek aromalı sütlü tatlı örneklerinde gerçekleştirilen analizler 3 tekrar 2 paralel olacak şekilde gerçekleştirilmiştir. Deneme verileri Duncan çoklu karşılaştırma testi ve varyans analizi (ANOVA) kullanılarak değerlendirilmiş, kuru 
madde, renk, doku bağımlı değişken homojen ve inhomojen dağılım ile yağ miktarı bağımsız değişkenler olarak alınmıştır. Duyusal analizlerden eşlenmiş kıyaslama testi sonuçları $\% 5$ önem düzeyinde gerekli yanıt sayıları tablosuna göre değerlendirilirken, puanlama testi sonuçları varyans analizi ile değerlendirilmiştir (Altuğ Onoğur ve Elmac1, 2015).

\section{SONUÇ VE TARTIŞMA}

\section{Kimyasal Özellikler}

Model sütlü tatlıların kuru madde ve yağ içerikleri Çizelge-3'de verilmiştir. Model tatlıların kuru madde oranlan1 \%23.74 ile \%24.29 arasinda değişmektedir. Kuru madde açısından, HOM3.5 ve İNHOM3.5 örnekleri arasinda ve HOM3.75 ile INHOM3.75 örnekleri arasında istatistiksel olarak anlamlı fark olmadığ belirlenmiştir $(P>0.05)$. Sütlü tatlı örneklerinin homojen veya homojen olmayan yapısının kuru madde üzerinde önemli bir etkisinin olmadığ1 görülmüştür. Model sütlü tatlı örneklerinin yağ değerleri arasındaki değişim istatistiksel olarak anlamlı bulunmuştur $(P<0.05)$. Homojen olmayan dağılıma sahip tatlı örneklerinin (İNHOM3.75 ve İNHOM3.5) yağ içeriğinde $\% 25$ ve $\% 30$ azalma ile benzer sonuçlar verdiği $(P>0.05)$ ve homojen olmayan dağılıma sahip örneklerin homojen dağılıma sahip örneklere göre daha düşük yağ içeriğine sahip olduğu belirlenmiştir.

Çizelge 3. Model sütlü tatlıların kuru madde, yağ içeriği ve renk değerleri ${ }^{1}$

Table 3. Dry matter, fat content and color values of model dairy desserts ${ }^{1}$

\begin{tabular}{|c|c|c|c|c|c|}
\hline \multirow{2}{*}{$\begin{array}{l}\text { Model } \\
\text { formülasyon } \\
\text { Model formulation }\end{array}$} & \multirow{2}{*}{$\begin{array}{c}\text { Kuru madde } \\
(\%) \\
\text { Dry matter }\end{array}$} & \multirow{2}{*}{$\begin{array}{c}\text { Yağ içeriği } \\
(\%) \\
\text { Fat content }\end{array}$} & \multicolumn{3}{|c|}{$\begin{array}{c}\text { Renk değerleri } \\
\text { Color values }\end{array}$} \\
\hline & & & $L^{*}$ & $a^{*}$ & $b^{*}$ \\
\hline $\begin{array}{l}\text { Kontrol } \\
\text { Control }\end{array}$ & $24.29 \mathrm{a} \pm 0.30$ & $4.67 \mathrm{a} \pm 0.13$ & $94.56^{a} \pm 0.01$ & $-2.28^{b} \pm 0.01$ & $11.09 \mathrm{~d} \pm 0.02$ \\
\hline HOM3.5 & $23.74^{b} \pm 0.20$ & $3.20 c \pm 0.01$ & $92.31 \mathrm{c} \pm 0.01$ & $-2.07 a \pm 0.01$ & $11.78^{c} \pm 0.01$ \\
\hline İNHOM3.5 & $23.74 \mathrm{~b} \pm 0.17$ & $2.06^{\mathrm{d}} \pm 0.14$ & $91.32 \mathrm{~d} \pm 0.01$ & $-2.51 \mathrm{c} \pm 0.25$ & $12.15^{b} \pm 0.02$ \\
\hline HOM3.75 & $24.27 \stackrel{a}{0} 0.37$ & $3.50^{\mathrm{b}} \pm 0.03$ & $93.09^{\mathrm{b}} \pm 0.01$ & $-2.09 \mathrm{a} \pm 0.02$ & $12.63^{a} \pm 0.02$ \\
\hline İNHOM3.75 & $24.22^{\mathrm{a}} \pm 0.55$ & $2.14 \mathrm{~d} \pm 0.13$ & $90.80 \mathrm{e} \pm 0.02$ & $-2.33^{b} \pm 0.01$ & $10.86 \mathrm{e} \pm 0.04$ \\
\hline
\end{tabular}

1: Küçük harfler satırlar arasında olmak üzere istatistiksel farklılı̆̆1 göstermektedir $(P<0.05)$.

1: Lower case letters shows the statistical difference between the lines $(P<0.05)$.

\section{Renk Değerleri}

Model sütlü tatlıların $L^{*}, a^{*}$ ve $b^{*}$ değerleri Çizelge 3'de verilmiştir. Sütlü tatlılarda yüksek $L^{*}$ değeri, ürünün beyazlık özelliğinin yüksek olduğunu göstermektedir (Bahçeci ve Acar, 2020). Sütlü tatlı örneklerinin $L^{*}$ değerleri arasında istatistiksel olarak anlamlı farkllilı bulunmuştur $(P<0.05)$. En yüksek $L^{*}$ değerinin kontrol örneğinde, en düşük $L^{*}$ değerinin ise İNHOM3.75 örneğinde görüldüğü belirlenmiştir. HOM3.5 ve INHOM3.5 örnekleri ile HOM3.75 ve INNHOM3.75 örnekleri karşılaştırıldığında, homojen dağllim gösteren örneklerin daha beyaz algilandığ1 tespit edilmiştir. Model tatlılar arasında $-a^{*}$ değerleri açısından istatistiksel olarak anlamlı bir fark olduğu tespit edilmiştir $(P<0.05)$. HOM3.5 ve HOM3.75 örneklerinin ise istatistiksel olarak benzer sonuçlar verdiği belirlenmiştir ( $P$ >0.05). Model sütlü tatlı örnekleri arasında $b^{*}$ değerleri açısından istatistiksel olarak anlamlı bir fark olduğu görülmüştür $(P<0.05)$. En yüksek $b^{*}$ değeri HOM 3.75 örneğinde görülürken, INHOM3.75 örneğinin en düşük $b^{*}$ değerine sahip örnek olduğu bulunmuştur. Yağ içeriği \%30 azaltılmış homojen ve homojen olmayan dağglım gösteren örnekler karşılaştırılldı̆ı̆nda, INHOM3.5 örneğinde HOM3.5 örneğine göre daha fazla sarllık tespit edilmiştir. Nitekim limon aromalı sütlü tatlllarda koyulaştırıcı tipi ve konsantrasyonu ile yağ içeriğinin renk, reoloji, in vivo aroma salınımı ve duyusal özellikler üzerindeki etkisinin araştırıldığı bir çalışmada, yağsız tatlı örneklerinde $L^{*}, b^{*}$ değerleri düşerken $a^{*}$ değerlerinin yükseldiği belirtilmektedir (Arancibia vd., 2015). 


\section{Doku özellikleri}

Model sütlü tatlıların doku analizi sonuçlan Çizelge 4'te verilmiştir. Sertlik değerleri arasındaki fark istatistiksel olarak anlamlı bulunmuş $(P$ $<0.05$ ), en yüksek yağ içeriğine sahip kontrol örneğinin en düşük sertliğe sahip olduğu ve yağ içeriği \%25 azaltılmış homojen olmayan dağılıma sahip tatlı örneğinin (INNHOM3.75) en yüksek sertliğe sahip olduğu belirlenmiştir. Homojen ve homojen olmayan dağllıma sahip örnekler karşılaştırıldığında, HOM3.5 ve İNHOM3.5 örnekleri ile HOM3.75 ve İNHOM3.75 örneklerinin sertlik değerleri benzer bulunmuştur. Model sütlü tatılıarın dış yapışkanlık değerleri incelendiğinde, $\% 5$ yağ içeriğine sahip kontrol örneği dışındaki diğer tatlı örneklerinin dış yapışkanlık değerleri arasındaki farkın istatistiksel olarak anlamlı olmadığ1 saptanmıştır $(P>0.05)$. Kontrol, HOM3.5, HOM3.75 ve INHOM3.5 örneklerinin elastikiyet değerleri arasında anlamlı bir fark $(P>0.05)$ olmadığı belirlenmekle birlikte, yağ içeriği yüksek örneklerde elastikiyet özelliğinin daha fazla olduğu ve en düşük elastikiyet değerinin İNHOM3.75 örneğinde olduğu belirlenmiştir. Gıdaların yapısal bütünlügünün korunmasında etkili olan iç yapışkanlık özelliğinin model sütlü tatlılarda 0.46 ile 0.54 arasinda değiştiği görülmektedir. HOM3.5, HOM3.75 ve INNHOM3.5 örnekleri ile HOM3.5, İNHOM3.5 ve INHOM3.75 örneklerinin iç yapışkanlık değerlerinin benzer sonuçlar verdiği $(P>0.05)$ ve kontrol örneğinin diğer örneklerden farklı olduğu belirlenmiştir. Farklı yă̆ içeriğine sahip sütlü tatlıların sakızımsılık değerleri arasında istatistiksel olarak anlamlı fark olduğu tespit edilmiştir ( $P$ $<0.05)$. En yüksek sakızımsılık değeri İNHOM3.75 örneğinde bulunmuştur. HOM3.5 ve INHOM3.5 örnekleri arasinda istatistiksel olarak anlamlı bir fark olmadığı $(P>0.05)$ ve benzer sakızımsılık özelliği gösterdiği bulunmuştur. Model sütlü tatlıların çiğnenebilirlik değerlerinin 164.57 ile 186.33 arasında değiştiği ve farklı yă̆ içeriğine sahip sütlü tatlıların çiğnenebilirlik değerleri arasında istatistiksel olarak anlamlı bir fark $\left(\begin{array}{l}P \\ >0.05\end{array}\right)$ olmadığ1 görülmüştür. HOM3.5 örneği dışında sütlü tatlı örneklerinin esneklik değerleri arasında anlamlı bir fark $(P>0.05)$ olmadığı, en düşük esnekliğe sahip örneğin HOM3.5 örneği, en yüksek esnekliğe sahip örneklerin ise INHHOM3.75, INNHOM3.5 ile kontrol örneği olduğu belirlenmiştir.

\section{Duyusal özellikler}

Eşlenmiş kıyaslama testi, HOM3.5 ve İNHOM3.5 örnekleri ile HOM3.75 ve INNHOM3.75 örnekleri arasında gerçekleştirilmiştir. Eşlenmiş kıyaslama testine göre HOM3.5 ve INHOM3.5 örnekleri arasinda ve HOM3.75 ve INHOM3.75 örnekleri arasında $\% 5$ güven eşiğinde istatistiksel olarak farklılık olduğu, homojen olmayan dağılıma sahip örneklerin homojen dağllim gösteren örneklerden daha yağlı olarak algılandığı belirlenmiştir.

Model sütlü tatlı örneklerinin puanlama testi sonuçları Çizelge 5'te verilmiştir. Sütlü tatlı örneklerinin görünüş değerleri arasında istatistiksel olarak anlamlı bir fark bulunmuştur $(P$ $<0.05$ ). Panelistler tarafindan yağ içeriği en yüksek olan kontrol örneğinin en düşük görünüş değerini aldığı ve ürünün hafif kaşıktan akan kıvamda olduğu tespit edilmiş ve tatlı yüzeyinde homojen olmayan renk dağılımları ifade edilmiștir. HOM3.5 ve İNHOM3.5 örnekleri ile HOM3.75 ve INNHOM3.75 örnekleri arasinda istatistiksel olarak anlamlı bir fark bulunmuştur $(P$ $<0.05)$. Homojen ve homojen olmayan dağılıma sahip örnekler karşılaştırıldığında, homojen olmayan dağılıma sahip örneklerde (INHOM3.5 ve INHOM3.75), ağızdan kıvam, homojen dağılıma sahip örneklere göre (HOM3.5 ve HOM3.75) daha yüksek alg1lanmıştır. Yağ içeriği \%25 oranında azaltılmış homojen (HOM3.75) ve homojen olmayan dağllima sahip örneklerin (İNHOM3.75), \%5 yağ içeriğine sahip olan kontrol örneğine göre daha fazla tercih edildiği görülmüştür. Homojen dağılım göstermeyen model sütlü tatlı örneklerinin (INNHOM3.5 ve İNHOM3.75) görünüş ve genel kabul edilebilirlik üzerinde olumsuz bir etkisinin olmadığ1 tespit edilmiştir. 
Çizelge 4. Model Sütlü tatlı örneklerinin doku analiz sonuçlar1 ${ }^{1}$ Table 4. Texture analysis results of model dairy desserts ${ }^{1}$

\begin{tabular}{|c|c|c|c|c|c|}
\hline $\begin{array}{l}\text { Model } \\
\text { formülasyon } \\
\text { Model } \\
\text { formulation }\end{array}$ & Control & HOM3.5 & İNHOM3.5 & HOM3.75 & İNHOM3.75 \\
\hline $\begin{array}{l}\text { Sertlik } \\
\text { Hardness (g) }\end{array}$ & $356.00^{c} \pm 18.19$ & $390.44^{b c} \pm 27.99$ & $440.55^{\mathrm{ab}} \pm 24.96$ & $436.67^{\mathrm{ab}} \pm 23.99$ & $475.52^{\mathrm{a}} \pm 24.24$ \\
\hline $\begin{array}{l}\text { Diş yapışkanlık } \\
\text { Adhesiveness (gs) }\end{array}$ & $-341.26^{a} \pm 18.97$ & $-398.16^{b} \pm 23.85$ & $-392.17^{b} \pm 20.26$ & $-403.75^{b} \pm 17.91$ & $-417.97^{b} \pm 30.31$ \\
\hline $\begin{array}{l}\text { Elastikiyet } \\
\text { Springiness }(\mathrm{mm})\end{array}$ & $0.88^{a} \pm 0.01$ & $0.85^{a} \pm 0.03$ & $0.84^{\mathrm{a}} \pm 0.04$ & $0.83^{a} \pm 0.04$ & $0.77^{b} \pm 0.04$ \\
\hline $\begin{array}{l}\text { İç yapişkanlık } \\
\text { Cobesiveness }\end{array}$ & $0.54^{a} \pm 0.02$ & $0.48^{\mathrm{bc}} \pm 0.02$ & $0.48^{\mathrm{bc}} \pm 0.02$ & $0.50^{\mathrm{b}} \pm 0.05$ & $0.46^{c} \pm 0.02$ \\
\hline $\begin{array}{l}\text { Sak1zımsilik } \\
\text { Gumminess (g) }\end{array}$ & $192.04^{b} \pm 26.69$ & $190.29 \mathrm{~b} \pm 26.74$ & $209.99 \mathrm{~b} \pm 23.48$ & $212.26^{\mathrm{ab}} \pm 25.71$ & $242.61^{\mathrm{a}} \pm 28.23$ \\
\hline $\begin{array}{l}\text { Çiğnenebilirlik } \\
\text { Chewiness (gs) }\end{array}$ & $168.48^{\mathrm{a}} \pm 24.84$ & $164.57 \mathrm{a} \pm 20.47$ & $181.33^{\mathrm{a} \pm 24.30}$ & $176.89 \mathrm{a} \pm 30.41$ & $186.33^{a} \pm 20.86$ \\
\hline $\begin{array}{l}\text { Esneklik } \\
\text { Resilience }\end{array}$ & $0.12^{a} \pm 0.01$ & $0.09^{\mathrm{b}} \pm 0.02$ & $0.11^{\mathrm{ab}} \pm 0.01$ & $0.10^{\mathrm{ab}} \pm 0.03$ & $0.11^{a} \pm 0.02$ \\
\hline
\end{tabular}

1: Küçük harfler sütunlar arasında olmak üzere istatistiksel farkliliğ1 göstermektedir $(P<0.05)$.

1: Lower case letters shows the statistical difference between the lines $(P<0.05)$.

Çizelge 5. Model Sütlü tatlı örneklerinin puanlama testi sonuçları ${ }^{1}$

Table 5 Scoring test results of model dairy desserts ${ }^{1}$

\begin{tabular}{lllll}
\hline $\begin{array}{l}\text { Model formülasyon } \\
\text { Model formulation }\end{array}$ & $\begin{array}{l}\text { Görünüş } \\
\text { Appearance }\end{array}$ & $\begin{array}{l}\text { Lezzet } \\
\text { Flavor }\end{array}$ & $\begin{array}{l}\text { Ağ1zda Kivam } \\
\text { Consistency in Mouth }\end{array}$ & $\begin{array}{l}\text { Genel Beğeni } \\
\text { Overall Acceptability }\end{array}$ \\
\hline $\begin{array}{l}\text { Kontrol } \\
\text { Control }\end{array}$ & $3.50^{\mathrm{c}} \pm 0.76$ & $2.5^{\mathrm{d}} \pm 0.89$ & $3.15^{\mathrm{b}} \pm 1.27$ & $3.15^{\mathrm{c}} \pm 0.88$ \\
HOM3.5 & $3.85^{\mathrm{bc}} \pm 0.93$ & $3.30^{\mathrm{cd}} \pm 0.80$ & $3.25^{\mathrm{b}} \pm 0.79$ & $3.25^{\mathrm{c} \pm 0.64}$ \\
INHOM3.5 & $3.60^{\mathrm{c}} \pm 0.99$ & $4.05^{\mathrm{ab}} \pm 0.83$ & $3.30^{\mathrm{b} \pm 0.86}$ & $3.85^{\mathrm{b}} \pm 0.49$ \\
HOM3.75 & $4.55^{\mathrm{a}} \pm 0.69$ & $3.65^{\mathrm{bc}} \pm 0.88$ & $4.20^{\mathrm{a}} \pm 0.77$ & $4.05^{\mathrm{ab}} \pm 0.69$ \\
INHOM3.75 & $4.35^{\mathrm{ab}} \pm 0.59$ & $4.55^{\mathrm{a}} \pm 0.83$ & $4.50^{\mathrm{a}} \pm 0.69$ & $4.35^{\mathrm{a}} \pm 0.59$
\end{tabular}

1: Küçük harfler satırlar arasında olmak üzere istatistiksel farklılı̆̆1 göstermektedir $(P<0.05)$.

1: Lower case letters shows the statistical difference between the lines $(P<0.05)$.

\section{SONUÇ}

Model bir sütlü tatlı örneğinde katmanlı yap1 oluşturularak homojen olmayan dağglım ile yağ azaltma işleminin gerçekleştirildiği bu çalş̧mada, en yüksek yağ içeriğine sahip kontrol örneğinin yüksek dış yapışkanlık, elastikiyet, iç yapışkanlık ve esneklik değerine sahip olduğu, ancak diğer formülasyonlardan daha yüksek yă̆ içeriğine sahip olması nedeniyle sertlik değerinin daha düşük olduğu belirlenmiştir. Çalışma sonucunda $\% 25$ oranında yağ içeriği azaltılmış homojen ve homojen olmayan dağllıma sahip tatlı örneklerinin (HOM3.75 ve INHOM3.75) diğer tatlı formülasyonlarına göre görünüş ve ağızda algilanan kıvam değerlerinin daha yüksek olduğu tespit edilmiş olup, homojen olmayan dağıllım ile yağ içeriği $\% 25$ oranında azaltılmış sütlü tatlı formülasyonu ile tüketicinin alg1ladığ1 lezzet değişmeden yağ miktarının azaltılabileceği belirlenmiştir. Homojen olmayan dağılımla yağ içeriğinin \%30 oranında azaltılabilmesinin de söz konusu olabileceği ancak üzerinde çalışılması gerektiği düşünülmektedir. Ayrıca bu çalışmada seçilen model sütlü tatlı dışında başka model örneklerde ileri araştırılmaların yapılması da önem taşımaktadır. 


\section{ÇIKAR ÇATIŞMASI BEYANI}

Yazarların başka kişiler ve/veya kurumlar ile çıkar çatışması bulunmamaktadır.

\section{YAZARLARIN KATKISI}

Müge BAYSAL, laboratuvar analizlerinin takibi, sonuçların değerlendirilmesi ve makalenin yazımını sağlamıştır. Yeşim ELMACI, araştırmanın planlanması, yürütülmesi ve sonuçların değerlendirilmesini sağlamıştır. Yazarlar makalenin son halini okuyup, incelemiş ve onaylamıştır.

\section{TEŞEKKÜR}

Bu çalışma Ege Üniversitesi Bilimsel Araştırma Projeleri Koordinasyon Birimi tarafindan desteklenmiştir. Proje No: FYL-2019-20683

\section{KAYNAKLAR}

AACC (1990). Am Assoc Cereal Chem., 8th Edition, St Paul. The USA.

Altuğ Onoğur, T., Elmac1, Y. (2015). Gidalarda Duyusal Değerlendirme. Sidas Medya Yayınları, İzmir, Türkiye, 148 s. ISBN: 978-9-9445-6608-7.

AOAC (1995). Official methods of analysis of the association of official analytical chemists. 16th Edition, Washington, DC.

Arancibia, C., Castro, C., Costell, E. and Bayarri, S., 2015, Colour, rheology, flavour release and sensory perception of dairy desserts. Influence of thickener and fat content, LWT-Food Sci. Tecbnol., 62(1): 408-416. Doi: https://doi.org/10.1016/ j.lwt.2014.08.024

Arcia, P.L., Costell, E., Tarrega, A. (2011). Inulin blend as prebiotic and fat replacer in dairy desserts: Optimization by response surface methodology. J. Dairy Sci., 94(5): 2192-2200. Doi: 10.3168/jds.2010-3873

Aytaç, F. (2017). Doğal tatlandırıcıların (stevia ve akçaağaç şurubu) sütlü tatlıların fiziksel, kimyasal ve tekstürel özellikleri üzerine etkisi. Namık Kemal Üniversitesi Fen Bilimleri Enstitüsü Gıda Mühendisliği Anabilim Dalı Yüksek Lisans Tezi, Tekirdağ, Türkiye, $117 \mathrm{~s}$.

Bahçeci, K.S., Acar, J. (2020). Renk analizi. http://web.hitit.edu.tr/dosyalar/duyurular/hulya
cakmak@hititedutr011220189A6L8V9X.pdf

(Erişim Tarihi: 18 Kasım 2020).

Bayarri, S., Chuliá, I., Costell, E. (2010). Comparing $\lambda$-carrageenan and an inulin blend as fat replacers in carboxymethyl cellulose dairy desserts. Rheological and sensory aspects. Food Hydrocoll., 24(6-7): 578-587. Doi: https://doi.org/10.1016/j.foodhyd.2010.02.004

Bayarri, S., Costell, E. (2009). Optimising the flavour of low-fat foods, Designing Functional Foods: Measuring and Controlling Food Structure Breakdown and Nutrient Absorption. Woodhead Publishing Series in Food Science, Technology and Nutrition, s. 431-452.

Borreani, J., Llorca, E., Quiles, A., Hernando, I. (2017). Designing dairy desserts for weight management: Structure, physical properties and in vitro gastric digestion. Food Chem., 220: 137-144. Doi: https://doi.org/10.1016/j.foodchem. 2016.09.202

Doğan, İ.S., Küçüköner, E. (1999). Düşük Yağ ve Kalori İçeren Gidaların Hazırlanmasında Yağ İkamelerinin Rolü. GID $A$, 24(6): 417-424. https://dergipark.org.tr/tr/pub/gida/issue/688 8/92171 (Erişim tarihi: 28 Ocak 2021)

Emorine, M., Septier, C., Thomas-Danguin, T., Salles, C. (2013). Heterogeneous salt distribution in hot snacks enhances saltiness without loss of acceptability. Food Res. Int., 51: 641-647. Doi: https://doi.org/10.1016/j.foodres.2013.01.006

Güzeler, N., Kacar, A., Say, D. (2011). Effect of milk powder, maltodextrin and polydextrose use on physical and sensory properties of low calories ice cream during storage. Academic Food Journal, 7: 6-12. Doi: http://dx.doi.org/10.12944/ CRNFSJ.4.

Liu, R., Wang, L., Liu, Y., Wu, T., Zhang., M. (2018). Fabricating soy protein hydrolysate/xanthan gum as fat replacer in ice cream by combined enzymatic and heat-shearing treatment. Food Hydrocoll., 81: 39-47. Doi: https://doi.org/10.1016/j.foodhyd.2018.01.031

Mosca, A.C., Rocha, J.A., Sala, G., Velde, F., Stieger., M. (2012). Inhomogeneous distribution of fat enhances the perception of fat-related sensory attributes in gelled foods. Food Hydrocoll., 
27, 448-455. Doi: https://doi.org/10.1016/ j.foodhyd.2011.11.002

Mosca, A.C., van de Velde, F., Bult, J.H.F., van Boekel, M.A.J.S., Stieger, M. (2010). Enhancement of swee,tness intensity in gels by inhomogeneous distribution of sucrose. FQAP, 21(7): 837-842. Doi: https://doi.org/10.1016/ j.foodqual.2010.04.010

Munsters, M.J.M., Saris, W.H.M. (2014). Body weight regulation and obesity: Dietary strategies to improve the metabolic profile. Annu Rev. Food Sci. Technol., 5: 39-51. Doi: 10.1146/annurevfood-030212-182557

Peker, H., Arslan, S. (2013). Effects of addition of locust bean gum on sensory, chemical, and physical properties of low-fat yoghurt. J Food Agric Env., 11-2: 274-277. Doi: https://doi.org/ $10.1234 / 4.2013 .4264$

Rodriguez Furlán, L.T., Campderrós, M.E. (2017). The combined effects of Stevia and sucralose as sugar substitute and inulin as fat mimetic on the physicochemical properties of sugar-free reduced-fat dairy dessert. Int. Gastron. Food Sci., 10: 16-23. Doi: https://doi.org/ 10.1016/j.ijgfs.2017.09.002

Sandrou, D.K., Arvanitoyannis, I.S. (2000). Low fat/calorie foods: Current state and perspectives.
Crit Rev Food Sci Nutr., ., 40: 427-447. Doi: 10.1080/10408690091189211

Serdaroğlu, M., Tömek, S. (1995). Yağı azaltılmış et ürünleri üretim tekniği. GIDA, 20(4): 237-241. https://dergipark.org.tr/tr/pub/gida/issue/699 8/93215 (Erişim tarihi: 28 Ocak 2021)

Siró, I., Kápolna, E., Kápolna, B., Lugasi, A. (2008). Functional food product development marketing and consumer acceptance-A review. Appetite, 51(3): 456-467. Doi: https://doi.org/ 10.1016/j.appet.2008.05.060

Syarifuddin, A., Septier, C., Salles, C., ThomasDanguin, T. (2016). Reducing salt and fat while maintaining taste: An approach on a model food system. FQAP, 59-69. Doi: https://doi.org/10.1016/j.foodqual.2015.08.009

Torres, I.C., Amigo, J.M., Knudsen, J.C., Tolkach, A., Mikkelsen, B.Ø., Ipsen, R. (2018). Rheology and microstructure of low-fat yoghurt produced with whey protein microparticles as fat replacer. Int Dairy J., 81:62-71. Doi: https://doi.org/10.1016/j.idairyj.2018.01.004

Verbeke, W. (2006). Functional foods: consumer willingness to compromise on taste for health? FQAP, 17: 126-131. Doi: https://doi.org/ $10.1016 /$ j.foodqual.2005.03.003 